\title{
Correction to: Development and Analysis of Multi-functional Beekeeping Loading Box Based on Electric Tracked Transport Vehicle
}

\author{
Pingan Wang ${ }^{1,2} \cdot$ Xiongzhe Han ${ }^{1,2} \cdot$ Youngsun Son ${ }^{1} \cdot$ Changyeun $\mathrm{Mo}^{1,2} \cdot$ Dongwon Kim $^{3} \cdot$ Subae Kim ${ }^{3}$. \\ Joonho Kim ${ }^{4}$. Wonki Chung ${ }^{5}$
}

Published online: 11 February 2022

(C) The Korean Society for Agricultural Machinery 2022

\section{Correction to: J. Biosyst. Eng.} https://doi.org/10.1007/s42853-021-00125-7

Due to an unfortunate mistake the $4^{\text {th }}$ author's name, Changyeon Mo, has been misspelt.

It should read: Changyeun Mo.

The original article has been corrected.

The online version of the original article can be found at https://doi.org/ 10.1007/s42853-021-00125-7

Xiongzhe Han

hanxiongzhe@kangwon.ac.kr

1 Department of Biosystems Engineering, College of Agriculture and Life Sciences, Kangwon National University, Chuncheon 24341, Republic of Korea

2 College of Agriculture and Life Sciences, Interdisciplinary Program in Smart Agriculture, Kangwon National University, Chuncheon 24341, Republic of Korea

3 Department of Agricultural Biology, The National Institute of Agricultural Science, RDA, Wanju 55365, Republic of Korea

4 Department of Electrical Information Control, Dongseoul University, Seongnam 13117, Republic of Korea

5 Onfarm Co., Ltd., Wanju 55365, Republic of Korea 